\title{
Mobility of the Cervical Spine in Women with Headaches: A Pilot Study
}

\author{
Adrian Kużdżał' ${ }^{1}$ Zuzanna Kłoda ${ }^{2}$, Zbigniew Wroński \\ 1Department of Physiotherapy, Institute of Health Sciences, Medical College of Rzeszów University, Rzeszów, Poland \\ 2Department of Rehabilitation, Faculty of Medicine, Medical University of Warsaw, Warsaw, Poland
}

Correspondence to: Adrian Kużdżał, kuzdzal.a@gmail.com

DOI: https://doi.org/10.5114/for.2021.106945

Received: 05.02.2021 Reviewed: 19.02.2021 Accepted: 19.02.2021

\section{Abstract}

Background: Cervical mobility is influenced by a number of factors, including headaches.

Aims: To assess the impact of headache and its clinical features on the range of movements of the cervical spine.

Material and methods: The study involved 25 women aged 30-54 who had headaches in the last 6 months. The respondents completed an original questionnaire, which included, inter alia, pain characteristics. The ranges of mobility of the cervical segment were measured using a smartphone held by a head-mounted setup. Rotation in the Occ-C2 segment was also assessed, and muscle tenderness was examined.

Results: The ranges of neck mobility in the study group did not differ from the ranges reported in the literature. There was no correlation between the pain characteristics and the ranges obtained, although correlations between age and a decrease in the mean ranges of mobility and between overweight and reduced mobility of the cervical segment were identified.

Conclusions: The occurrence, duration, frequency, and intensity of headaches do not significantly affect the range of motion of the cervical spine.

\section{Key words}

cervical spine, range of movements (ROM), headaches, diagnostics 


\section{Introduction}

One of the most common reasons for neurological consultations is headaches, which are occurring with increasing frequency in modern society. About $90 \%$ of people experience headaches at least once in their lifetime, $20-47 \%$ of the population suffers from frequent headaches, and about $2-5 \%$ of the population experiences chronic headaches $[1,2]$.

Like any experience of pain, headaches are a subjective sensation. They are becoming more common in almost every age group. When experiencing a headache, patients complain of decreased quality of life and decreased ability of everyday functioning. Studies describe the following negative consequences of headaches: a decline in cognitive function, attention, concentration, and memory and movement slowness [1, 3-5].

The International Headache Society describes over 300 different types of headache [6]. Among these, cervicogenic headaches are assumed to be associated with disorders and dysfunctions of the cervical spine or reduced cervical mobility $[1$, 7-9].

This paper presents practical aspects related to the possibility of physiotherapeutic diagnosis of cervicogenic headaches.

\section{Aims}

The aim of this study was (1) to assess the mobility of the upper cervical spine in female patients with headache and (2) to evaluate the influence of the duration, frequency, and intensity of headaches on the range of motion of flexion, extension, rotation, and lateral flexion (tilt) of the cervical spine.

\section{Material and methods}

\section{Study group}

A total of 25 women aged 30-56 years participated in the study, with a mean age of 44.5 years $(\mathrm{SD}=7.4$ years). All subjects were included in the study according to the established criteria.
The inclusion criteria for the study were as follows: (1) age between 30 and 60 years, (2) no previous history of head and/or cervical trauma and/or surgery within the past 5 years, (3) presence of headache within the past 6 months, and (4) no headache at the time of the study. In contrast, the study exclusion criteria were: (1) age of $<30$ or $>60$ years, (2) previous history of trauma, head and/or neck surgery within the past 5 years, (3) headache at the time of the study, and (4) general poor wellbeing.

The range of body mass index (BMI) of the subjects was $18.07-29.38 \mathrm{~kg} / \mathrm{cm} 2$, with a mean value of $24.66 \mathrm{~kg} / \mathrm{cm} 2$. One subject was underweight $(\mathrm{BMI}<18.5 \mathrm{~kg} / \mathrm{cm} 2), 14$ subjects were overweight (BMI $>24.99 \mathrm{~kg} / \mathrm{cm} 2)$, and the remaining 10 subjects were at normal weight. In this study, 17 people rated their health as good and 8 people as average. Among the participants' occupations were teacher, psychologist, office worker, trader, taking care of the household, and others (Fig. 1).

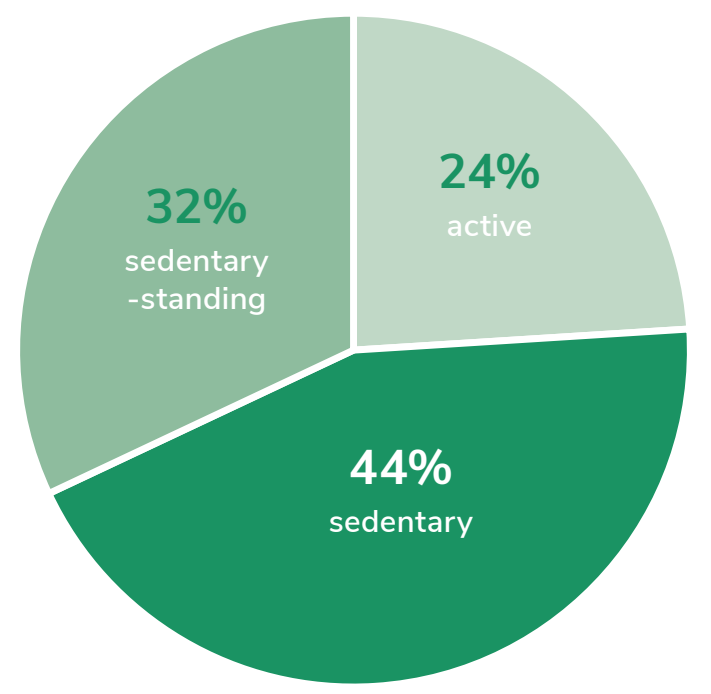

Figure 1. Type of work in relation to physical activity. 


\section{Research methodology}

In this study, an original survey questionnaire was used to collect data on the group of women with headaches selected for the study. The questionnaire contained 27 questions covering patient data and headache characteristics. Moreover, we examined cervical spine mobility during active movements and evaluated muscle tenderness.
The range of motion of the cervical spine of the subjects was measured using a smartphone and the Rotating Sphere application for flexion, extension, and lateral flexion measurements (Fig. 2) and the Digital Compass application for rotation measurements (Fig. 3). The smartphone was in a holder fixed to a headband.
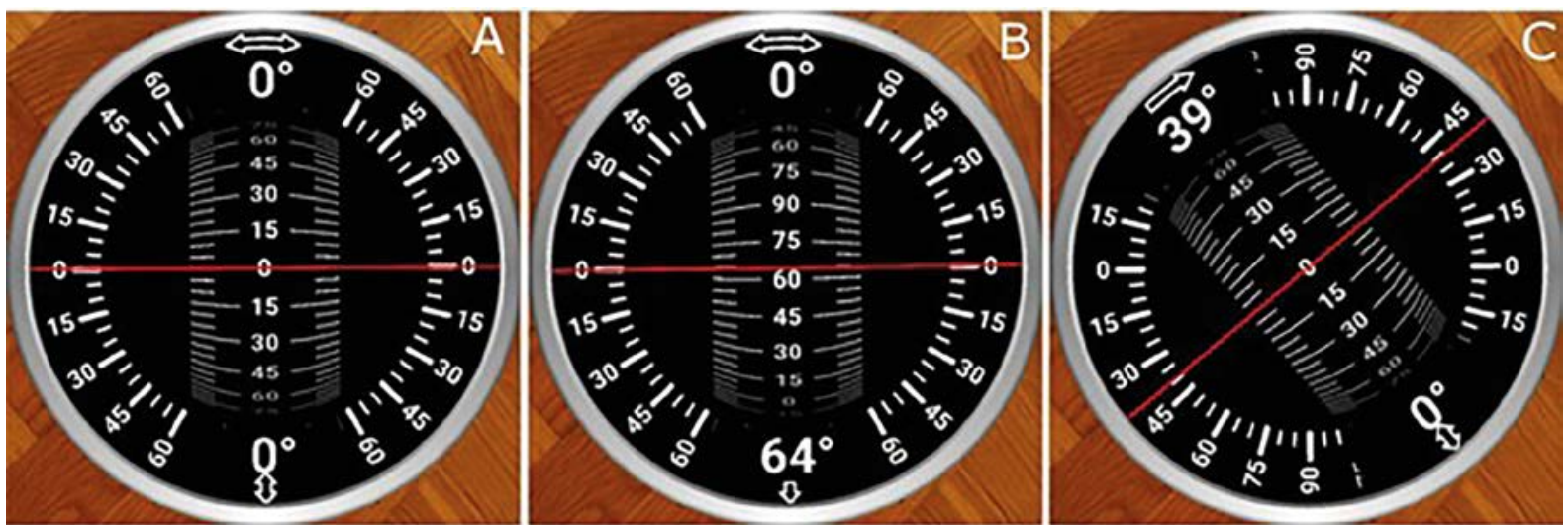

Figure 2. Images from the Rotating Sphere application during the test ( $\mathrm{A}$ - starting position, $\mathrm{B}$ - flexion measurement, and $\mathrm{C}$ - lateral flexion measurement)
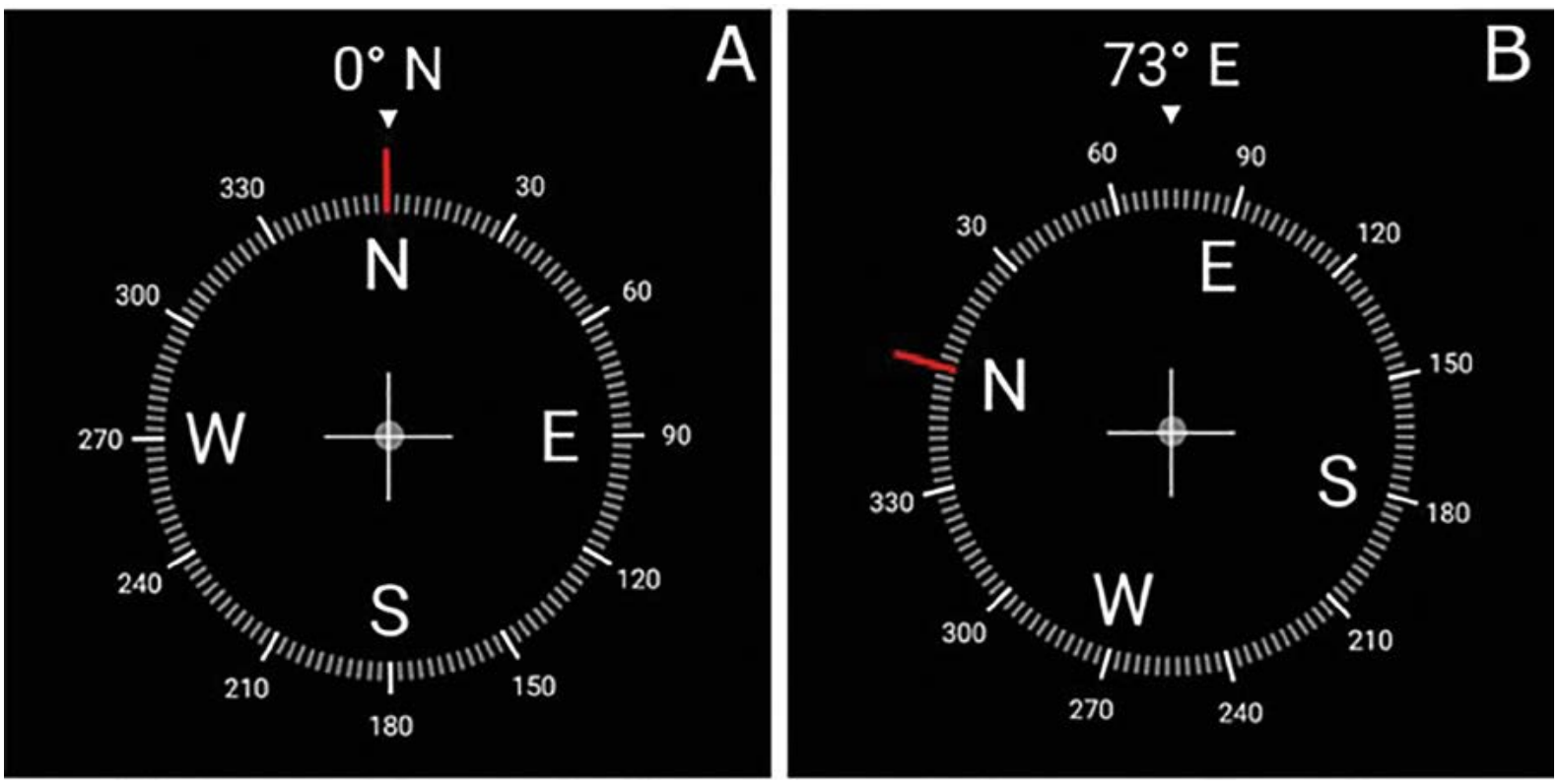

Figure 3. Images from the Digital Compass application during the rotation test ( $A$ - starting position and $B$ - final position) 
All movements were tested in an upright sitting position. The subject was sitting unsupported and looking forward. The Frankfort horizontal plane was parallel to the floor, the feet were kept flat on the floor, and the upper limbs relaxed on the thighs. Before the task, the patient was carefully instructed on how to perform it. The smartphone was positioned perpendicular to the floor during the measurement of flexion, extension, and lateral flexion movements (Figs. 4 and 5). The smartphone was subsequently positioned parallel to the floor during the measurement of the rotation movements (Fig. 6). The device was calibrated in the neutral (starting) position, and the results were read after reaching the maximum range of movement in the tested plane. In order to increase the reliability of the results and reduce their randomness, two measurements were taken for each movement and the arithmetic mean was calculated. During the study, the subjects were asked about pain and other discomforts they may have experienced during the head movements.
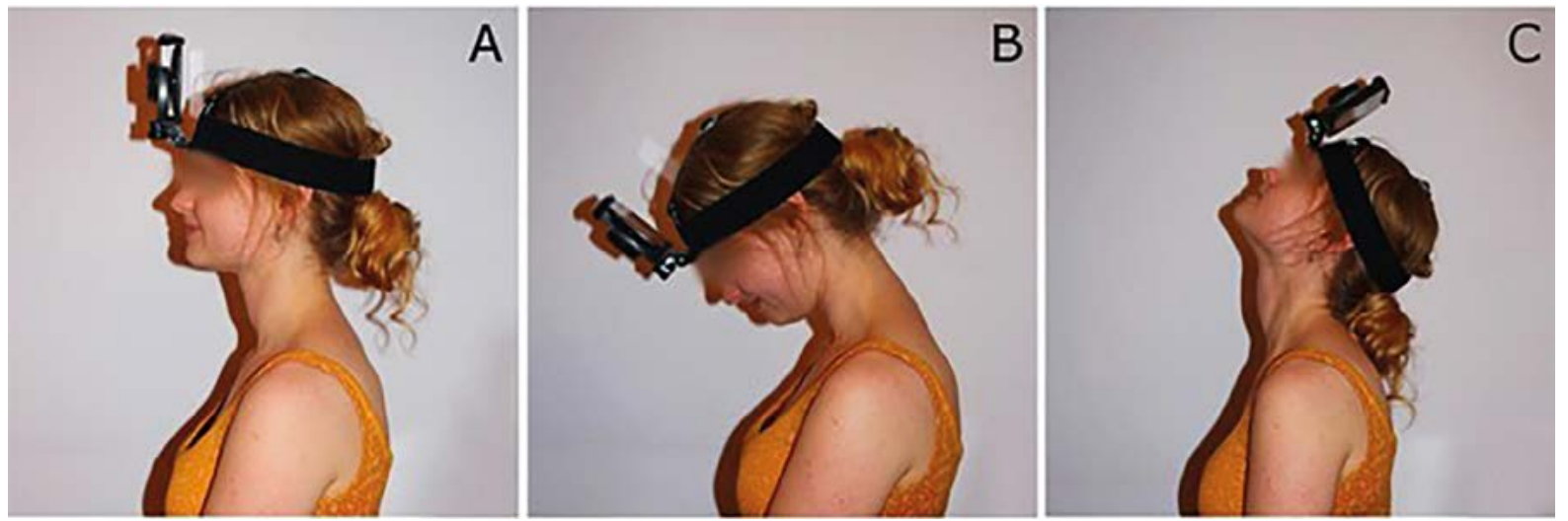

Figure 4. Measurement of flexion and extension movements ( - starting position, $B$ - final position in flexion, and $C$ final position in extension)
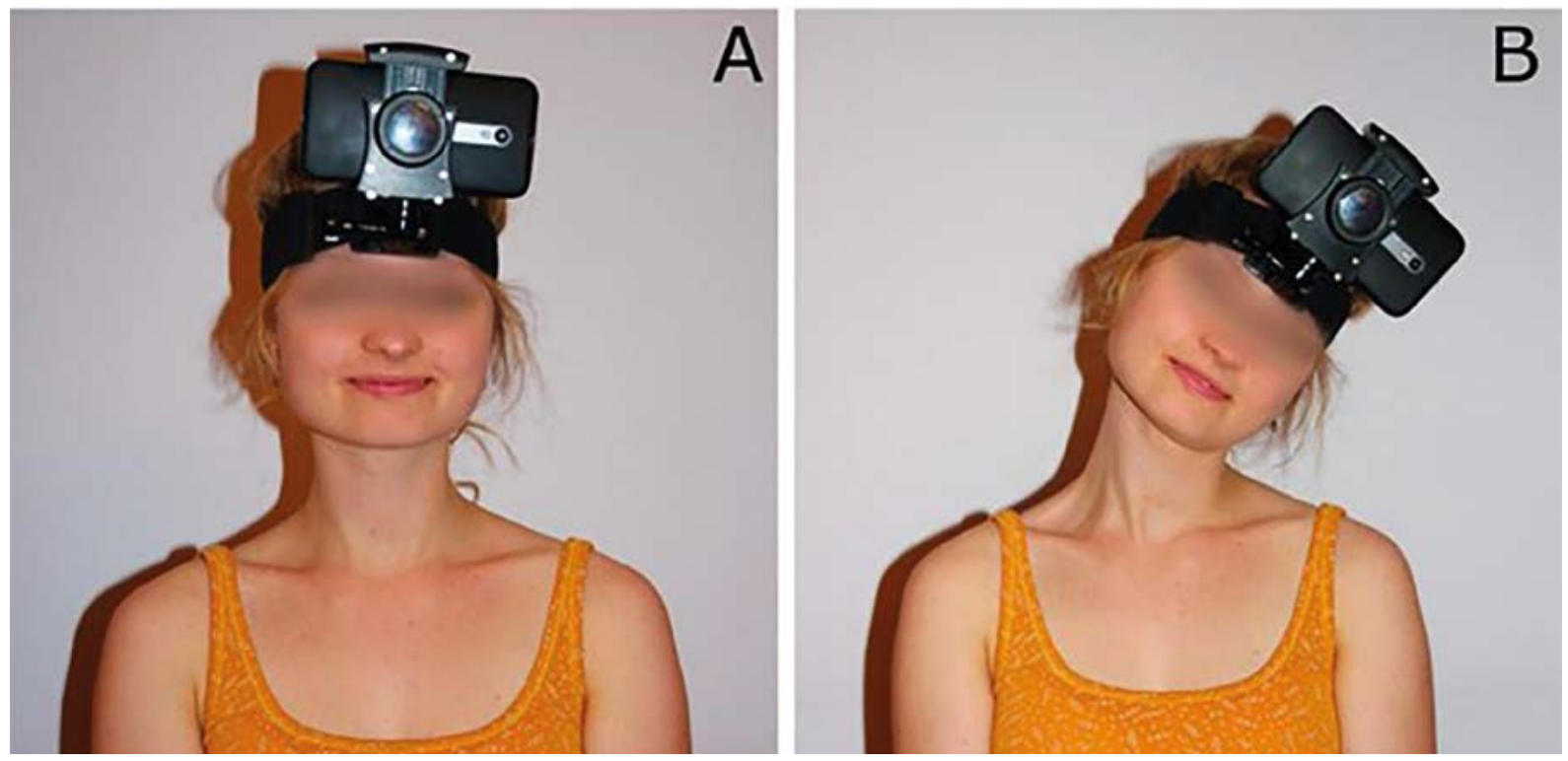

Figure 5. Measurement of lateral flexion movement ( $A$ - starting position and $B$ - final position) 

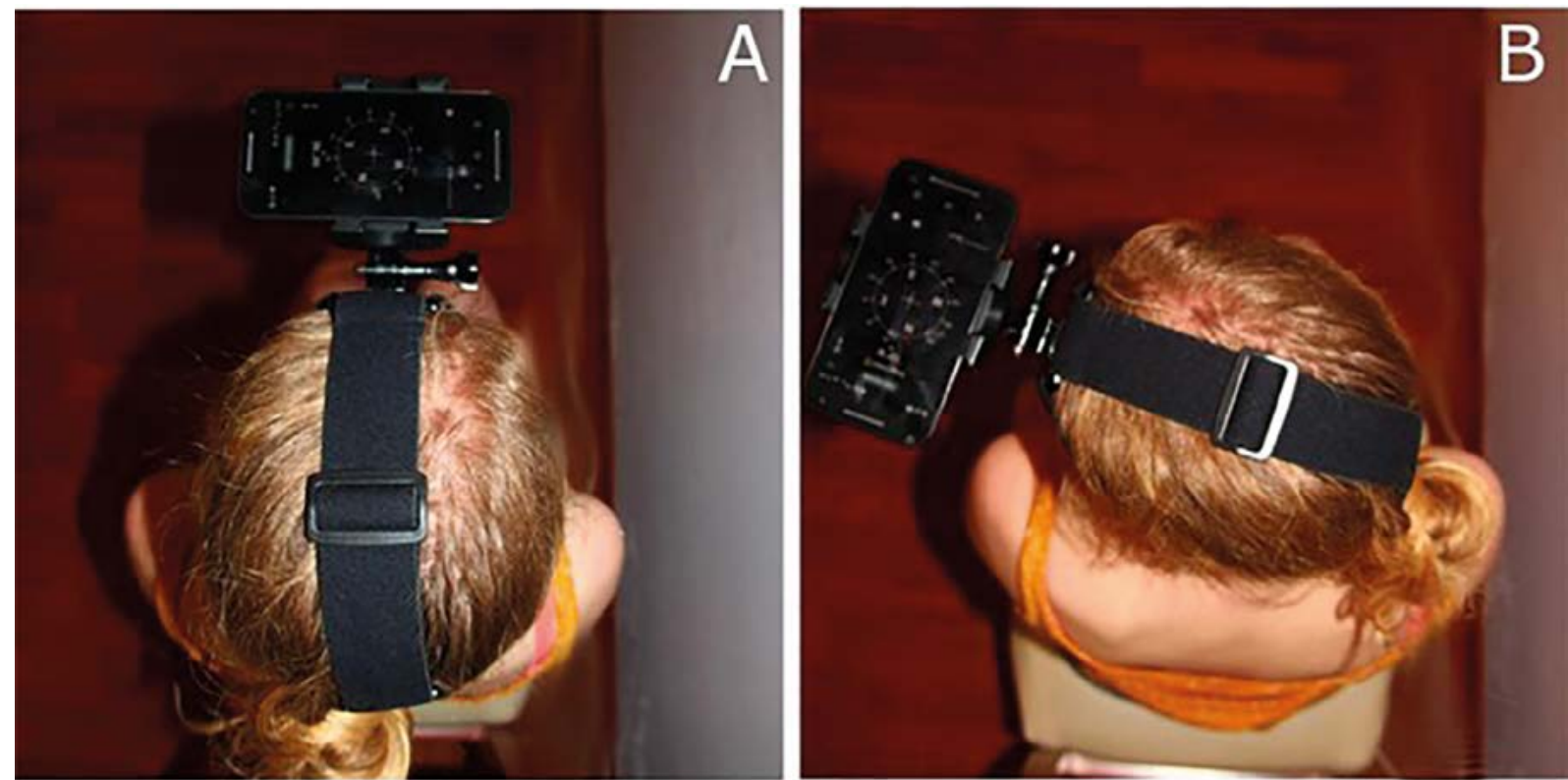

Figure 6. Measurement of flexion movement ( $A$ - starting position and $B$ - final position)

The next stage was the assessment of the $\mathrm{C} 0-\mathrm{C} 2$ segment rotation. The subject was in a sitting position, and the researcher stood behind the subject with the thumb and index finger of one hand stabilising the $\mathrm{C} 2$ vertebra and with the other hand placed on the head (Fig. 7). By performing passive left and right rotation movements until a clear resistance was felt, it was subjectively assessed by observation which way the movement was smoother and which way a greater range of rotation was possible to reach.
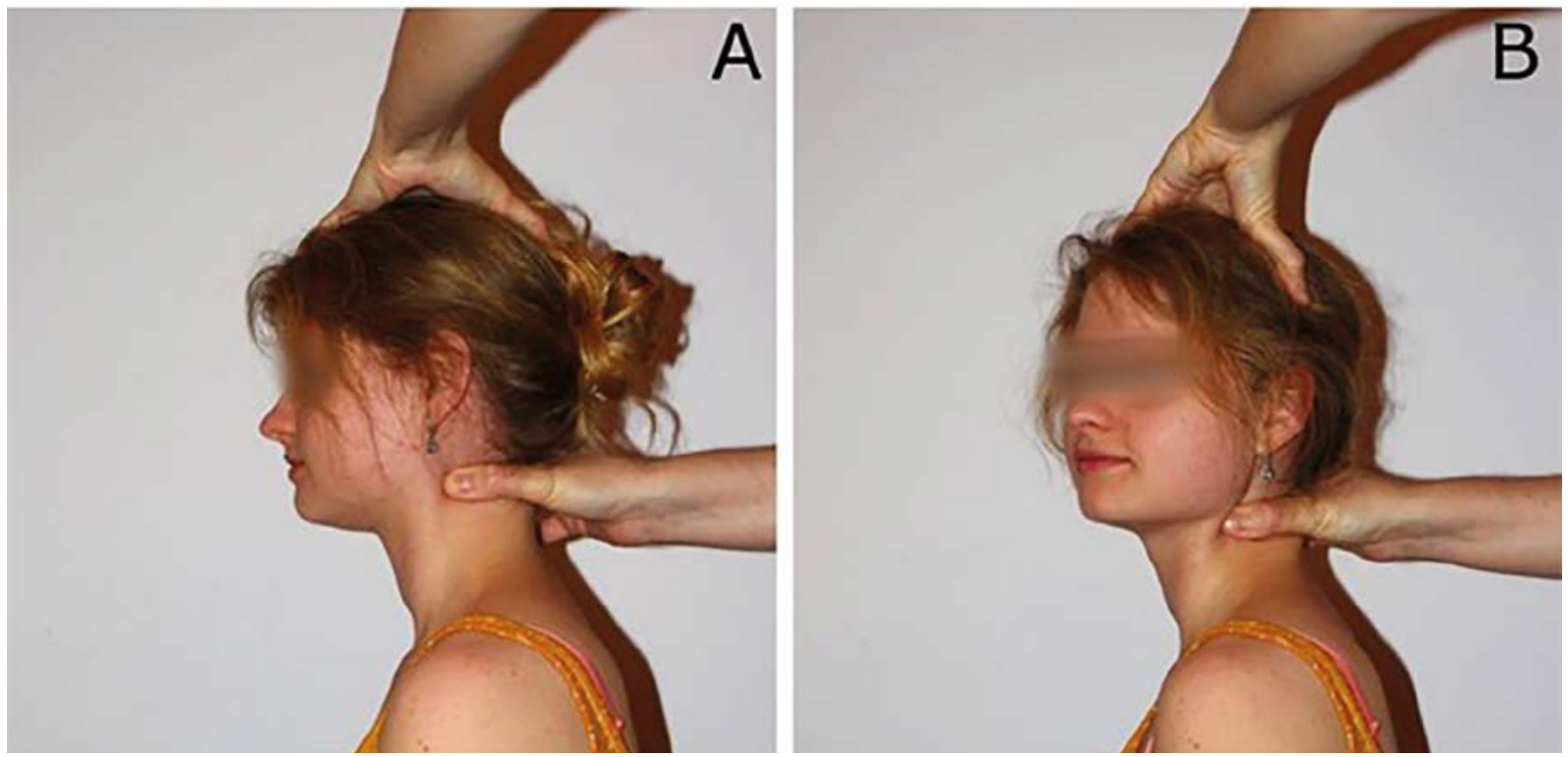

Figure 7. Test of $\mathrm{CO}-\mathrm{C} 2$ segment rotation ( $\mathrm{A}$ - starting position and $\mathrm{B}-$ final position) 
The tenderness of the suboccipital muscles, cervical region, and descending part of the trapezius muscle were also assessed by palpation. If the subject reported tenderness, discomfort, or pain at any point, they were asked to rate these complaints on a scale from 1 to 10 .

The analysis of the obtained data for the study sample was performed using Excel. Basic descriptive statistics, such as range, mean, and standard deviation, were used to summarise the study findings.

\section{Results}

All subjects reported the occurrence of headaches in the last six months (Fig. 8).

The onset of headache in the cervical or occipital region occurred in 14 subjects (more than $50 \%)$. The headache did not start in the neck or the occipital region in 11 people. Pain was not unilateral in 11 people (this is important because migraine, by definition, does not change sides).

In the diagrams below, the subjects could mark the areas in which they felt the headache (Fig. 9). The more intense the colour, the more often a given area was chosen. It should be noted that the most frequent areas of headache are the forehead, the occipital and temporal regions, and the top of the head.

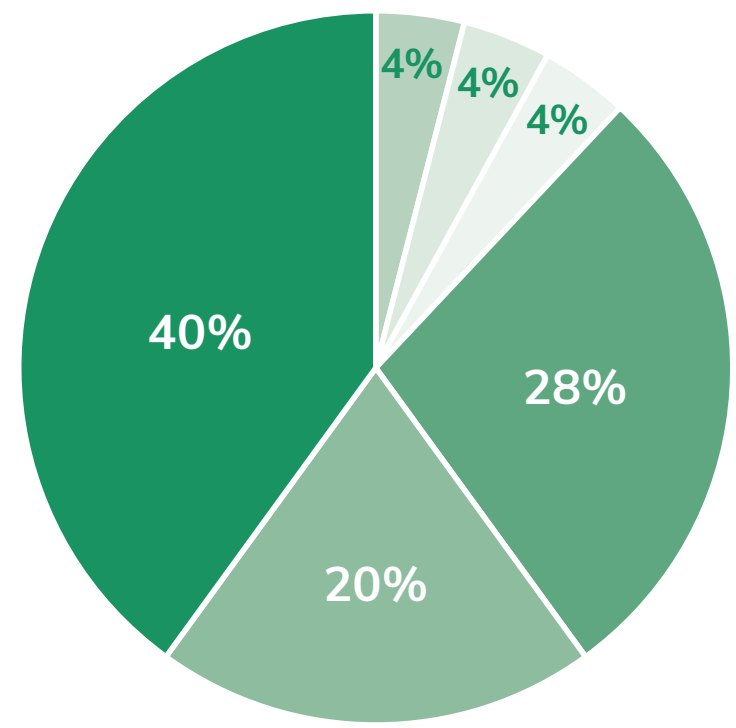

several times a month

once a week

several times

several times a week

once a month

every day

Figure 8. Frequency of headache occurrence
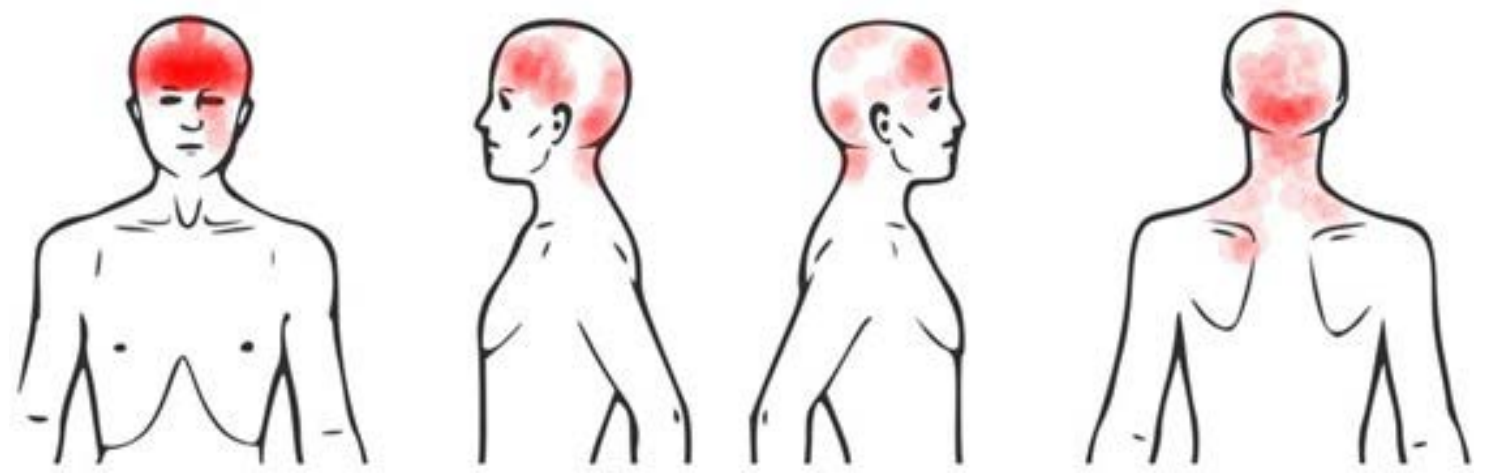

Figure 9. Headache patterns among the study subjects 
In this study, 12 subjects indicated that there were positions that reduced the headache, and 15 subjects responded that physical activity increased the headache. The intensities of the headaches on a scale from 0 to 10 were presented as follows: two persons described the intensity of the pain as 4 , two persons as 5 , four persons as 6 , four persons as 7 , five persons as 8 , four persons as 9 , and four persons described the experienced headache as the most severe in their lives, as 10.

Figure 10 illustrates how the subjects characterised the nature of the headaches (they could choose more than one answer).

The subjects were able to determine subjectively whether they perceived a restriction in cervical mobility. It was found that 9 subjects felt no restriction, 14 felt slight restriction, and 2 felt significant restriction. In the next part of the study, the cervical spine mobility was measured (Table 1).

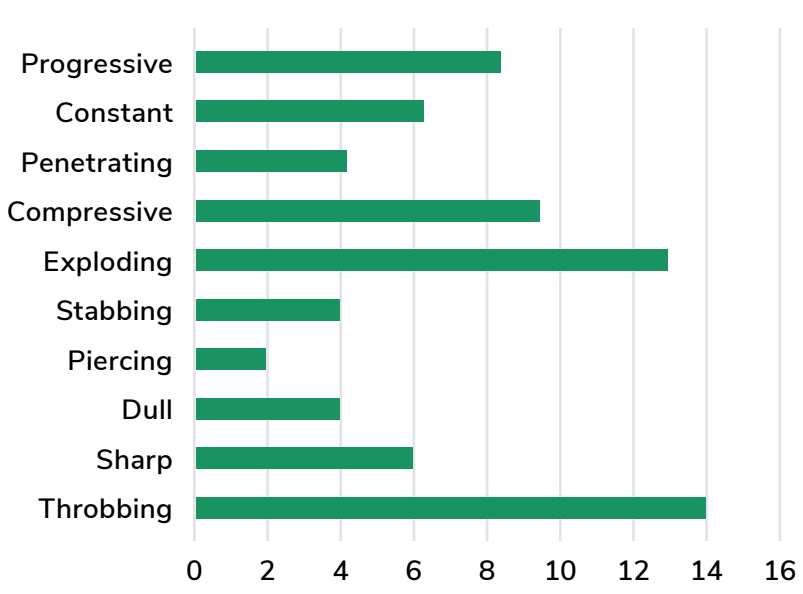

Figure 10. Nature of pain experienced

Table 1. Range of motion of the cervical spine

\begin{tabular}{|c|c|c|c|}
\hline Movement & ROM ( ${ }^{\circ}$ ) & M & 8.6 \\
\hline Flexion & $43-81$ & 63.7 & 13.4 \\
\hline Extension & $41-90$ & 41.1 & 10.2 \\
\hline Lateral flexion - right & $22.5-61$ & 41.4 & 10.9 \\
\hline Lateral flexion - left & $21-61$ & 76.1 & 13.8 \\
\hline Rotation - right & $38.5-90$ & 74.24 & 14.7 \\
\hline
\end{tabular}

Legend: ROM - range of movement, $\mathrm{M}$ - mean, SD - standard deviation.

It was found that during measurements, 5 subjects reported cervical pain: 2 subjects during rotation, 2 during extension, and 1 during flexion. During the subjective assessment of $\mathrm{C} 0-\mathrm{C} 2$ segment mobility, 13 subjects noted smoother movement, less resistance, or a greater range of rotation to one side. During muscle palpation, 19 subjects reported sensations of discomfort, tenderness, or pain. Of these, 12 subjects felt these discomforts in the suboccipital muscle region, 6 during palpation of the cervical region, and 14 on the trapezius muscle. The range of pain was scored between 1 and 8 on a scale from 0 to 10 .

In addition to parameters directly related to headache, the correlation between age and the cervical ranges of motion was also tested. The results are shown in Table 2. 
Table 2. Age and the mean ranges of motion in the cervical spine

\begin{tabular}{|c|c|c|c|c|c|c|}
\hline Movement Age & Flexion & Extension & $\begin{array}{c}\text { Lateral } \\
\text { flexion - } \\
\text { right }\end{array}$ & $\begin{array}{c}\text { Lateral } \\
\text { flexion - } \\
\text { left }\end{array}$ & $\begin{array}{c}\text { Rotation - } \\
\text { right }\end{array}$ & $\begin{array}{c}\text { Rotation - } \\
\text { left }\end{array}$ \\
\hline $30-39$ & 60.7 & 74.4 & 50.7 & 53.3 & 82.5 & 79.4 \\
\hline $40-49$ & 67.3 & 63.4 & 43.5 & 39.9 & 73.7 & 75.7 \\
\hline $50-59$ & 63 & 55.7 & 31.1 & 33.6 & 73.5 & 68.7 \\
\hline
\end{tabular}

It can be observed that the mean range of motion of the cervical segment in all movements except left lateral flexion and right rotation gradually decreased with age in the study group. The subjects with normal BMIs $(<25)$ had greater mean ranges of motion in all movements except left lateral flexion and right rotation by about $3-9^{\circ}$ than the overweight subjects.

\section{Discussion}

Headache is a condition that most of the population experiences at least once in their lifetime [1]. Over the years, hundreds of different types of headaches have been identified [6], all of which may co-occur in the same patient, making diagnostic and therapeutic management considerably more difficult. Cervicogenic headache is a relatively recent and understudied condition that presents a challenge to contemporary medicine.

The measurements showed no differences from the values reported in the literature [10-12]. In 2014, Raymond et al. conducted a study of cervical mobility in 400 healthy subjects using the Cervical Range of Motion (CROM) device [13]. The subjects were divided by age. The study showed that age was accompanied by a reduction in the mean range of motion in all directions, a trend also observed in the present study. In 2018, Rodríguez-Sanz et al. conducted research on 25 individuals with chronic cervical pain, comparing measurements obtained using the CROM device and two smartphone apps
[14]. The authors found excellent reliability and validity of the apps compared to the CROM method in all spine movement tests. By contrast, a 2013 study by Tousignant-Laflamme et al. noted that measurements of cervical mobility using two iPhone apps and a CROM device in healthy subjects showed good reliability and validity of the apps used [15]. Other investigations have also demonstrated the good functionality and reliability of smartphone apps in assessing cervical mobility [16, 17].

The CROM device is recommended for measuring the cervical ranges of motion as the method with the highest reliability, validity, and accuracy among available devices and methods [18]. However, it is an expensive device, and the presented studies indicate that freely available smartphone applications can be successfully used in everyday practice as a convenient solution, since almost everyone has a smartphone. The results obtained in the present study were similar to the values reported by authors who also measured the cervical ranges of motion using a smartphone application. The methodology for cervical mobility testing described in our paper enhances the diagnostic possibilities of physiotherapists in their everyday practice while maintaining the highest possible objectivity during the testing and treatment process.

Once the cervical mobility ranges were measured, the next part of the outcome analysis attempted to find a factor coexisting with cervical spine mobility restrictions (implicitly affecting these 
restrictions). In 2009, Bevilaqua-Grossi et al. conducted a study in which cervical mobility was measured in 45 women aged 20-54 years, suffering from migraines and having episodic migraine pain, and the results were compared with a control group [19]. The examination was performed using the CROM device. The characteristics of headaches occurring in the subjects were also assessed (frequency, duration of problem, duration of single attack, location of pain, pain intensity during movement, pain during measurement, and unilaterality of pain). A reduced range of motion was found in subjects with migraines compared to the control group, especially in the range of extension, left lateral flexion, and right rotation. There was no correlation between age and range of motion. In addition, the assessed parameters related to the headache did not affect the range of cervical motion. There was also no correlation between the side on which the symptoms manifested and the restriction of movement to that side. In the present study, however, it was observed that the mean range of motion of the cervical segment decreased with age in all movements except flexion and right rotation. Similar to BevilaquaGrossi et al. [19], parameters related to headaches did not affect the reduction of cervical range of motion in any movement.

In 2007, Jull et al. conducted a study to assess cervical musculoskeletal impairment in subjects with headaches [20]. The participants were diagnosed and assigned to groups suffering from migraines, tension-type headaches, and cervicogenic headaches. One of the parameters studied was the range of motion of the cervical region using Fastrak, a three-dimensional measurement system. The study showed a significant reduction in cervical mobility in subjects with cervicogenic headaches during extension and left and right rotations compared to the other headache groups. The ranges of motion of subjects with migraines and tension headaches were not significantly different from those of the control group.
The present study did not attempt to diagnose the subjects; however, the study group included participants with a decreased range of rotation or extension, subjects whose headaches began in the occipital or cervical region, and subjects who experienced unilateral headache-which may indicate cervicogenic headache as the primary or one of many headaches occurring in the respective subjects. The headache symptoms of the patients may also provide a clue about the type of headache they were experiencing. However, due to the multitude of headache types and the lack of diagnostic experience, it was not possible to determine which type of headache was present in specific individuals. It was also not possible to assess the percentage distribution of headache prevalence in the study group. The study subjects might have experienced several types of headaches, which may mask themselves. There is no doubt that headaches, including cervicogenic ones, reduce quality of life and the ability of normal functioning [21, 22]. Further studies on a larger population and in comparison to a control group without headache symptoms are recommended. Research conducted on individuals with headaches at the time of the study would also be worthwhile, albeit much more difficult to undertake.

\section{Conclusions}

Based on the results of the preliminary pilot study presented and discussed in this paper, the following conclusions can be drawn: (1) the occurrence of headache has no significant effect on the ranges of motion of the cervical spine; (2) the duration, frequency, and intensity of headache has no significant effect on the ranges of motion of the cervical spine; (3) the smartphone is a device that can be used to study the ranges of motion of the cervical spine in physiotherapy practice. 


\section{References}

1. Konecki K, Kochański B, Zukow W, Hagner W. Cervical headaches - selected techniques by Brian Mulligan method. J Health Sci. 2013; 3 (16): 75-86.

2. Page P. Cervicogenic headaches: an evidence-led approach to clinical management. Int J Sports Phys Ther. 2011; 6 (3): 254-266.

3. Hall T, Briffa K, Hopper D. Clinical evaluation of cervicogenic headache: a clinical perspective. J Man Manip Ther. 2008; 16 (2): 73-80.

4. van Suijlekom HA, Lame I, Stomp-van den Berg SG, Kessels AG, Weber WE. Quality of life of patients with cervicogenic headache: a comparison with control subjects and patients with migraine or tension-type headache. Headache 2003; 43: 1034-1041.

5. Kocjan J. Quality of life of patients with cervicogenic headaches. Jakość życia pacjentów z bólem głowy pochodzenia szyjnego. J Educ Health Sport. 2016; 6 (1): 1381146.

6. Headache Classification Committee of the International Headache Society. The International Classification of Headache Disorders. Cephalalgia 2018; 38 (1): 11211.

7. Patel N, Bigal ME, Kolodner K, Leotta C, Lafatta J, Lipton RB. Disability and healthrelated quality of life in strict migraine vs probable migraine (migrainous headache) and control subjects within a health plan. Cephalalgia 2004; 11th Congress of the International Headache Society.

8. Dodick DW. Chronic daily headache. N Engl J Med. 2006; 354: 158-165.

9. Howard PD, Behrns W, Martino MD, DiMambro A, McIntyre K, Shurer C. Manual examination in the diagnosis of cervicogenic headache: a systematic literature review. J Man Manip Ther. 2015; 23 (4): 210-218.

10. Olson KA. Manual Physical Therapy of the Spine. St. Louis: Elsevier; 2009.

11. Kapandji AI. Anatomia Funkcjonalna Stawów, tom 3. Wrocław: Elsevier Urban \& Partner; 2014.

12. Porzych P, Ratuszek-Sadowska D, Pyskir M, Simińska J, Ogurkowski K, Kitschke E. Cervical vertebral column - mobility and selected ways of measurement - a literature review. J Educ Health Sport. 2016; 6 (6): 505-516.
13. Swinkels RA, Swinkels-Meewisse IE. Normal Values for Cervical Range of Motion. Spine 2014; 39 (5): 362-367.

14. Rodríguez-Sanz J, Carrasco-Uribarren A, Cabanillas-Barea S. et al. Validity and reliability of two Smartphone applications to measure the lower and upper cervical spine range of motion in subjects with chronic cervical pain. J Back Musculoskelet Rehabil. 2019; 32 (4): 619-627.

15. Tousignant-Laflamme Y, Boutin N, Dion AM, Vallée CA. Reliability and criterion validity of two applications of the iPhone ${ }^{\mathrm{TM}}$ to measure cervical range of motion in healthy participants. J Neuroeng Rehabil. 2013; 10 (1): 69.

16. Quek J, Brauer SG, Treleaven J, Pua YH, Mentiplay B, Clark RA. Validity and intra-rater reliability of an Android phone application to measure cervical range-of-motion. J Neuroeng Rehabil. 2014; 11: 65.

17. Guidetti L, Placentino U, Baldari C. Reliability and Criterion Validity of the Smartphone Inclinometer Application to Quantify Cervical Spine Mobility. Clin Spine Surg. 2017; 30 (10): 1359-1366.

18. Williams MA, McCarthy CJ, Chorti A, Cooke MW, Gates S. A Systematic Review of Reliability and Validity Studies of Methods for Measuring Active and Passive Cervical Range of Motion. J Manipulative Physiol Ther. 2010; 33 (2): 138-155.

19. Bevilaqua-Grossi D, Pegoretti KS, Goncalves MC, Speciali JG, Bordini CA, Bigal ME. Cervical Mobility in Women With Migraine. Headache: J Head and Face Pain 2009; 49 (5): 726-731.

20. Jull G, Amiri M, Bullock-Saxton J, Darnell R, Lander C. Cervical Musculoskeletal Impairment in Frequent Intermittent Headache. Part 1: Subjects With Single Headaches. Cephalalgia 2007; 27(7), 793-802.

21. Falsiroli Maistrello L, Rafanelli M, Turolla A. Manual Therapy and Quality of Life in People with Headache: Systematic Review and Meta-analysis of Randomized Controlled Trials. Curr Pain Headache Rep. 2019; 23 (10): 78

22. Demir YP, Sumer MM. Effects of smartphone overuse on headache, sleep and quality of life in migraine patients. Neurosciences (Riyadh). 2019; 24 (2): $115-121$ 